\title{
Hurricane Harvey and climate change: the need for policy to protect children
}

\author{
Susan E. Pacheco ${ }^{1}$
}

M any of us witnessed first-hand the tragedy of the families and children displaced by Hurricane Katrina arriving to the Houston shelters in 2005. Recent news reports, with eerily similar devastation unfolding in Texas after Hurricane Harvey, are a grim reminder of the impact that extreme weather events have on children as our climate continues to change. With its landfall as a category 4 hurricane, the massive flooding caused by the unprecedented 33 trillion gallons of rain, the over 200,000 homes damaged or destroyed, thousands of rescues and over 34,000 people in shelters, Hurricane Harvey stands as one of the most destructive hurricanes in history. Current tallies indicate that up to 3 million children in the state have been impacted by the hurricane and over 1 million children were unable to start school on time (1). Houston shelters are teeming with rescue stories and volunteers helping to provide resources to meet the basic needs of thousands of individuals. Hundreds of families, with children of all ages, are sleeping among strangers on cots that concealed their precious belongings. Of concern for the health of children are drinking water and flood water contamination with waste water from sewers and other toxic pollutants (2). The exposure to toxic substances in potentially damaged Superfund sites, the threat posed by the explosion of the Arkema chemical plant in Crosby, Texas and the release of the carcinogen benzene by an industrial site close to the largely Hispanic Manchester community near the Ship Channel only compounds the stress of the impacted families and the health concerns they may face.

Climate change is caused by the release of heat trapping greenhouse gases mainly from human combustion of fossil fuels and agricultural activities https://www.ipcc.ch/pdf/assess ment-report/ar5/syr/SYR_AR5_FINAL_full.pdf. These anthropogenic greenhouse gas emissions have increased since the preindustrial era, leading to atmospheric concentrations of carbon dioxide, methane, and nitrous oxide that are unprecedented in at least the last 800,000 years and resulting in warming of the ocean and the atmosphere. This warming has resulted in melting of the glaciers and ice sheets, changes in temperature extremes, droughts and heavy precipitation events, and sea level rise. Fueled by warmer sea surface temperatures, hurricanes like Hurricane Harvey, with higher peak wind

intensity and precipitation, are expected to become increasingly common. The devastation caused by these extreme weather events is increased by the flooding associated to sea level rise and storm surges https:/www.ipcc.ch/pdf/assessment-report/ ar5/syr/SYR_AR5_FINAL_full.pdf.

The 2015 American Academy of Pediatrics (AAP) technical report on climate change contains a comprehensive description of the changing climate effects on children's health (3). The unique vulnerability of children, including their dependence on caregivers, and their physical, behavioral, emotional, developmental, and psychological immaturity, make them more susceptible to the deleterious effects of extreme weather events and natural disasters that we will experience. These vulnerabilities are compounded by the environmental injustice conditions inherent in our society and defined by cultural and ethnic differences, geographic location, and socioeconomic status.

The environmental disruption created by the changing climate, resulting in extreme weather events, heat waves, droughts and floods, poor air quality, increase in infections and infectious vectors disproportionately affect the pediatric population. The resulting population displacement after extreme weather events can have a serious toll on children's health. After Hurricane Katrina more than 160,000 children in Louisiana and Mississippi were displaced, more than 5,000 children were reported missing after Hurricanes Katrina and Rita, and about 50,000 Louisiana and Mississippi children missed school in the 2005-2006 school year. Approximately $\sim 15,000$ children did not attend in the 2006-2007 school year. Of particular concern are the impacts caused by extreme weather events on the emotional and mental health of children such as PTSD, anxiety, academic difficulties, and depression.

Extreme weather events like Hurricane Harvey magnify the social and economic disparities affecting the poor and ethnic minorities. Low-income and minority communities like Manchester and Galena Park, close to the Houston Ship Channel, are more vulnerable to extreme weather events as many homes are more susceptible to storm shock, are located close to flood-prone areas, near oil refineries, toxic waste sites, or petrochemical plants. The release of the carcinogen

${ }^{1}$ Department of Pediatrics, University of Texas Mc Govern Medical School, Houston, Texas

Correspondence: SE. Pacheco (Susan.E.Pacheco@uth.tmc.edu)

Received 4 October 2017; accepted 14 October 2017; advance online publication 6 December 2017. doi:10.1038/pr.2017.280 


\section{Commentary | Pacheco}

benzene from a nearby oil refinery and the spill of almost a half-million gallons of gasoline from storage tanks along the Houston Ship Channel bear witness to the threats and struggles these communities face.

The real tragedy of hurricanes such as Hurricane Harvey is that they will continue to occur as the climate continues to change. In less than a month, we have witnessed the devastation caused by Hurricanes Harvey, Irma, and Maria affecting millions of people in the Caribbean Islands and the United States, destroying entire communities and causing indescribable hardship and suffering. Unless we engage in mitigation activities to curb greenhouse gas emissions we will continue to experience similar environmental catastrophes. Our understanding of the unique vulnerability of children means that pediatricians must educate families and the public on the connection between climate change and children's health. We must assume a position of leadership to promote the implementation of public health policies advocating for the curbing of greenhouse gas emissions and the implementation of adaptation measures. The wellbeing of children should be the priority in any advocacy initiative having to do with climate change. Although we have made improvements in the care of family units and children in the immediate aftermath of disasters like Hurricane Harvey, we need to advocate for comprehensive, systematic preparedness before and after extreme weather events and other catastrophes that we will continue to experience. Pediatricians and local professional associations should participate in regional disaster preparedness teams and advocate for a multidisciplinary approach with professionals in fields having to do with children's health. These efforts should take into account resources to address medical problems, injuries and death, infections, psychosocial needs, displacement, homelessness, disruption of social environments, and health care infrastructure.

The implementation of a roadmap for adaptation measures and preparedness must be in place at the local, state, national, and international levels. Measures to address social disparities in vulnerable communities with limited resources should be delineated. Publications from the AAP, Pediatric Environmental Health Specialty Units (PEHSU), and many other educational and preparedness resources can facilitate the development of these initiatives $(3,4)$. It is imperative to engage in research activities to understand and establish safeguards to protect the immediate needs and the mental health of children exposed to natural disasters as the future of our planet rests on the shoulders of healthy, thriving individuals. Climate change brings an unprecedented scenario to the history of mankind and a threat to the overall wellbeing of all living organisms in the planet. We have the moral responsibility to advocate for the implementation of mitigation measures to decrease the generation of greenhouse gases, and for the protection of children during extreme weather events and other catastrophes resulting from this crisis. In the process, we should continue to ask ourselves if we are doing enough.

\section{STATEMENT OF FINANCIAL SUPPORT}

No financial support was received for this commentary.

Disclosure: The authors declare no conflict of interest.

\section{REFERENCES}

1. UNICEF Life After Harvey: Bringing Order to the Chaos https://www. unicefusa.org/stories/life-after-harvey-bringing-order-chaos/32809 (Accessed 11 September 2017).

2. EPA EPA/TCEQ Harvey Update: Air Quality Improving, More Water Systems Operational https://www.epa.gov/newsreleases/epatceq-harveyupdate-air-quality-improving-more-water-systems-operational (Accessed 8 September 2017).

3. Ahdoot S, Pacheco SE, Council on Environmental Health. Global Climate Change and Children's Health. Pediatrics 2015;136:e1468-84.

4. Disaster Preparedness Advisory Council; Committee On Pediatric Emergency Medicine. Ensuring the Health of Children in Disasters. Pediatrics 2015;136:e1407-17. 